\title{
Testing Positive for SARS-CoV-2 in Two Countries 105 Days Apart
}

\section{Tshokey Tshokey ${ }^{1}$, Jamyang Choden ${ }^{2}$, Lila Adhikari ${ }^{3}$,} Binay Thapa ${ }^{3}$, Sonam Wangchuk ${ }^{3}$

${ }^{1}$ Department of Pathology and Laboratory Medicine, Jigme Dorji Wangchuck National Referral Hospital, Thimphu, Bhutan;

${ }^{2}$ International Health Regulation, Ministry of Health, Thimphu, Bhutan;

${ }^{3}$ Royal Centre for Disease Control, Ministry of Health, Thimphu, Bhutan

Received January 27, 2021; Accepted August 5, 2021.

Key words: Bhutan - COVID-19 - Czech Republic - SARS-CoV-2

Abstract: Recovered COVID-19 patients may test positive for SARS-CoV-2 for a long time from intermittent shedding of viral fragments. A 36-year-old man who tested positive for SARS-CoV-2 in the Czech Republic and recovered tested positive again in Bhutan, 105 days beyond his first positive test. He experienced minimal symptoms and recovered without complications. Although no virological test was conducted to rule out reinfection, the repeat positive test after initial recovery likely resulted from prolonged shedding of dead viral particles than a reinfection.

Mailing Address: Dr. Tshokey Tshokey, Department of Pathology and Laboratory Medicine, Jigme Dorji Wangchuck National Referral Hospital, Menkhang Lam, Thimphu 11001, Bhutan; e-mail: doc_tshokey@yahoo.com 


\section{Introduction}

With a toll of 118,754,336 confirmed cases and 2,634,370 deaths globally as of $14^{\text {th }}$ March 2021 (World Health Organization, 2021), the COVID-19 pandemic is either at its peak or in its second/third wave in different countries. As countries open up, concerns on an effective vaccine, lasting protective immunity and reinfection or reactivation have become critical. Initial suspicions of reinfection or reactivation from South Korea (Smith, 2020) and Switzerland (Ravioli et al., 2020) were refuted and explained by the detection of non-viable, non-infectious viral fragments for prolonged period in some recovered patients. However, reinfections have been established in Hongkong, Europe (Winter, 2020), India (Ghanekar, 2020) and the list is increasing with 64 confirmed cases as of $14^{\text {th }}$ March 2021 (BNO News, 2020). However, the significance of reinfection in the purview of emerging mutations and vaccinations is debatable.

As part of its stringent COVID-19 preventive measures, Bhutan has instituted a 21-day mandatory facility quarantine of all people coming into the country since $31^{\text {st }}$ March 2020. People in quarantine are tested on 3-5 days (by RT-PCR Real-time Polymerase Chain Reaction), 13-14 days (by Rapid antibody test and RT-PCR) and on the completion of quarantine (by Rapid antibody test). Additionally, an individual is tested on arrival at the Point of Entry or any time during the quarantine (by RT-PCR), if symptomatic. Any individual confirmed to be positive for SARS-CoV-2 by a RT-PCR is isolated in government hospitals regardless of symptoms and severity. After isolation, patients are tested on day seven (asymptomatic) or after three days of symptom free period (symptomatic). Anyone with two negative RT-PCR reports 24 hours apart is deisolated into a government designated facility for another 14 days before discharging home.

We report a case of a 36-year-old Bhutanese man who tested positive for SARS-CoV-2 in the Czech Republic and recovered but tested positive again in Bhutan 105 days beyond the first positive test.

\section{Case report}

A 36-year-old Bhutanese man was in the Czech Republic on a student exchange program since the first week of March 2020. He shared accommodation in a tworoom apartment with five students of different nationalities. Within a week after his arrival into the university, the Czech Republic went into a national lockdown due to the ongoing COVID-19 pandemic. By the end of March 2020, all of his five roommates tested positive for COVID-19 and isolated. He continued to stay in his residence and was tested positive on $3^{\text {rd }}$ April 2020, by RT-PCR test. He was immediately isolated into a single room in the university's guest house. The individual claimed that he has never stepped out of his accommodation after the lockdown and suspected that he contracted the virus from his roommates.

At the time of testing positive, he did not have any symptoms except for a minimal dry cough which he had for some time even before his arrival into the Czech 
Republic. However, after two days of isolation, he experienced loss of sense of smell, taste and loss of appetite which lasted for 3-4 days. He also had one episode of high fever on the third night of isolation which responded well to antipyretics. No other medications were provided. His cough became more frequent but was not worse. He thought drinking lots of green tea and hot water mixed with black pepper and ginger helped his throat and cough. After a week in isolation, he became symptom free and his taste, smell and appetite returned, although he still tested positive on $17^{\text {th }}$ April 2020, two weeks after the first confirmation. Finally, after three weeks of isolation, he tested negative on $27^{\text {th }}$ April 2020, and was de-isolated into a single occupancy in the university's dormitory until he departed for Bhutan on the $28^{\text {th }}$ of June 2020 . He arrived in Bhutan on the $29^{\text {th }}$ of June 2020 and was directly put into facility quarantine, as per the existing protocol for arrivals into the country. During the quarantine, he did not have any signs and symptoms but underwent tests as per the quarantine testing protocol.

\section{Test assays and results}

At the time of testing the case, Bhutan was using the World Health Organization (WHO) approved primer sequences from Da An Gene Co., Ltd. (China) Detection kit for 2019 Novel Coronavirus (2019-nCoV) - that targets ORF1ab and $\mathrm{N}$ genes of SARS-CoV-2. The kit includes an endogenous internal control detection system used for monitoring the processes of specimen collection, RNA and PCR amplification, and thereby reducing false negative results. The kit claimed an analytical sensitivity of 500 viral copies $/ \mathrm{ml}$. Any sample with an obvious amplification curve and a cycling threshold (Ct) value $\leq 40$ was judged as positive for 2019 novel Coronavirus (Da An Gene Co., Ltd.).

Test assay details and report of tests conducted in the Czech Republic were not available. However, the individual confirmed that he was subjected to a nasopharyngeal swab sample for RT-PCR. He was not tested for SARS-CoV-2 antibody in the Czech Republic.

As per the existing testing protocol of facility quarantine, the individual was subjected to a RT-PCR on third day of quarantine which was negative. On the $14^{\text {th }}$ day (July $\left.16^{\text {th }}, 2020\right)$, he underwent RT-PCR and Rapid antibody test (SD Biosensor, Korea). He tested positive for SARS-CoV-2 gene (Ct value of $\mathrm{N}$ gene was 31.9 and ORF1ab gene was 34.9) and for SARS-Covi-2 antibody (IgG), 105 days after his first positive test $\left(3^{\text {rd }}\right.$ April to $16^{\text {th }}$ July 2020). Following this, he was isolated into a hospital facility. He was deisolated on the $24^{\text {th }}$ of July after testing twice negative in RT-PCR.

\section{Discussion}

To our knowledge, this was one of the first report of a COVID-19 patient testing positive again in 105 days after the first positive test, during the early period of the pandemic. In Bhutan's experience, laboratory confirmed COVID-19 cases took 
about 12 days on average until they turn negative in RT-PCR (range 7-46 days), after the first confirmation. In one of the first reports of prolonged viral shedding, a 71-year-old woman in Wuhan was reported to have a documented viral shedding for up to 60 days from the onset of symptoms which was one of the longest durations of viral shedding reported (Li et al., 2020). There are several similar reports of prolonged viral shedding as well as testing positive again after initial negative test and recovery (Gousseff et al., 2020; Luo, 2020; Ravioli et al., 2020; Duggan et al., 2021). Concerns on whether these repeat positivity after initial clinical recovery or confirmed negative by RT-PCR were due to reinfections or reactivation have been refuted and explained as resulting from prolonged intermittent shedding of dead, non-viable virus in respiratory epithelial cell turn-over (Smith, 2020). Recently, there was growing concern on reinfection from mutated virus with reports from Hongkong, Europe and India (Ghanekar, 2020). Increasing number of evidences have confirmed the concept of reinfection in at least 64 cases to date (BNO News, 2020). However, confirming that the repeat positive case is due to reinfections with different strain of the virus require advanced laboratory capacity in culturing viruses from the cases and analysis through gene sequences which is not possible in many laboratories especially in developing countries such as Bhutan. Reinfections are scientifically confirmed only when genomic analysis of SARS-CoV-2 show genetically significant differences between each variant associated with each instance of infection. This was demonstrated in a 25-year-old male patient in Nevada (USA), who also experienced more severe symptoms compared to his first episode (Tillett et al., 2021).

Although reinfection was not ruled out, we opine that the case in description was a typical occurrence of prolonged and intermittent shedding of dead non-viable virus after clinical recovery. This is based on the high Ct value in RT-PCR, presence of IgG against SARS-CoV-2 and the individual remaining symptomless during confirmation. It is also due to such occurrence that many countries have shifted from test-based discharge to time-based discharge. The World Health Organization and countries such as Singapore and South Korea, recommend the discharge of COVID-19 patients between 14-21 days after the first laboratory confirmation (Ministry of Health, Singapore, 2020). Learning from these cases, Bhutan may need to adopt the time-based discharge criteria in order to avoid prolonged hospital stay of patients who may be shedding dead and non-infectious virus particles.

Testing of recovered patients are not recommended due to the occurrence of repeat positives after recovery and discharge leading to exhaustive public health control measures and diversion of diagnosis of other medical conditions, in countries like Singapore (Ministry of Health, Singapore, 2020). However, with recent evidence of reinfections, testing of recovered patients may need to be reviewed especially in a setting with wide community outbreak. Nonetheless, the fact that the case in description had no symptoms and was $\lg G$ positive with a definite history of testing negative after initial laboratory confirmation of infection should point largely towards 
a prolonged shedding of dead viral fragments rather than reinfection of reactivation. Additionally, in the absence of laboratory capacity to perform viral load and gene sequencing, the $\mathrm{Ct}$ value (high in the described case) with seroconversion may be used to estimate the time or stage of infection and indications of recovery.

\section{Conclusion}

Despite increasing reports of reinfections in many countries, we conclude that the case in description was a typical case of prolonged shedding of viral particles after recovery from previous infection. However, with increasing reports of mutations and reinfections, counties should build clinical and virological expertise to exclude emergence of new variants and reinfection in the community.

\section{References}

BNO News (2020) COVID-19 reinfection tracker. BNO News. Available at: https://bnonews.com/index. php/2020/08/covid-19-reinfection-tracker/

Duggan, N. M., Ludy, S. M., Shannon, B. C., Reisner, A. T., Wilcox, S. R. (2021) Is novel coronavirus 2019 reinfection possible? Interpreting dynamic SARS-CoV-2 test results. Am. J. Emerg. Med. 39, 256.e1-256.e3.

Ghanekar, N. (2020) Reinfection cases in India show virus mutating, experts say more research needed to reveal impact on vaccine. News18. Available at: https://www.news18.com/news/india/reinfection-casesin-india-show-virus-mutating-genetic-changes-in-2nd-samples-put-vaccine-efficiency-in-question-2889813. html

Gousseff, M., Penot, P., Gallay, L., Batisse, D., Benech, N., Bouiller, K., Collarino, R., Conrad, A., Slama, D., Joseph, C., Lemaignen, A., Lescure, F. X., Levy, B., Mahevas, M., Pozzetto, B., Vignier, N., Wyplosz, B., Salmon, D., Goehringer, F., Botelho-Nevers, E.; in behalf of the COCOREC study group (2020) Clinical recurrences of COVID-19 symptoms after recovery: Viral relapse, reinfection or inflammatory rebound? J. Infect. 81, 816-846.

Li, J., Zhang, L., Liu, B., Song, D. (2020) Case report: Viral shedding for 60 days in a woman with COVID-19. Am. J. Trop. Med. Hyg. 102, 1210-1213.

Luo, A. (2020) Positive SARS-Cov-2 test in a woman with COVID-19 at 22 days after hospital discharge: a case report. Journal of Traditional Chinese Medical Sciences 7, 413-417.

Ministry of Health, Singapore (2020) Revised Discharge Criteria for COVID-19 Patients. Available at: https:// www.moh.gov.sg/news-highlights/details/revised-discharge-criteria-for-covid-19-patients

Ravioli, S., Ochsner, H., Lindner, G. (2020) Reactivation of COVID-19 pneumonia: A report of two cases. J. Infect. 81, e72-e73.

Smith, J. (2020) South Korea reports more recovered coronavirus patients testing positive again. Reuters. Available at: https://www.reuters.com/article/us-health-coronavirus-southkorea/south-korea-reportsmore-recovered-coronavirus-patients-testing-positive-again-idUSKCN21V0JQ

Tillett, R. L., Sevinsky, J. R., Hartley, P. D., Kerwin, H., Crawford, N., Gorzalski, A., Laverdure, C., Verma, S. C., Rossetto, C. C., Jackson, D., Farrell, M. J., Van Hooser, S., Pandori, M. (2021) Genomic evidence for reinfection with SARS-CoV-2: a case study. Lancet Infect. Dis. 21, 52-58.

Winter, L. (2020) Patients reinfected with coronavirus in Hong Kong, Europe. The Scientist Magazine ${ }^{\circledR}$

Available at: https://www.the-scientist.com/news-opinion/patients-reinfected-with-coronavirus-in-hongkong-europe-67869

World Health Organization (2021) WHO Coronavirus Disease (COVID-19), January 24, 2021. Available at: https://covid19.who.int/

Tshokey T.; Choden J.; Adhikari L.; Thapa B.; Wangchuk S. 